\title{
Effects of Antemortem Ingestion of Ethanol on Insect Successional Patterns and Development of Phormia regina (Diptera: Calliphoridae)
}

\author{
KIMBERLY L. TABOR, RICHARD D. FELL, CARLYLE C. BREWSTER, KEVIN PELZER, ${ }^{1}$ \\ AND GEORGE S. BEHONICK ${ }^{2}$
}

Department of Entomology, Virginia Polytechnic Institute and State University, Blacksburg, VA 24061-0319

J. Med. Entomol. 42(3): 481-489 (2005)

\begin{abstract}
The effects of antemortem ingestion of ethanol by domestic pigs, Sus scrofa L., on postmortem insect successional patterns and the development of Phormia regina (Meigen) were studied during summer 2003 in Blacksburg, VA. Insect samples were collected from the carcasses of ethanol-treated and untreated pigs for $10 \mathrm{~d}$ postmortem during two successional studies. In total, 32 insect taxa were collected during the two studies, with 29 and 27 taxa observed on the carcasses of ethanol-treated and untreated pigs, respectively. The earliest arrivers to both carcass types were dipterans. This group was represented by six families, with $P$. regina and Phaenicia coeruleiviridis (Macquart) being the most common calliphorids. Beetles in six families were collected on the carcasses of ethanol-treated pigs, but only three of the families were collected on carcasses of the untreated pigs. Permutation analyses to test the null hypothesis of no similarity between successional patterns of insect taxa from carcasses of ethanol-treated and untreated pigs showed that the successional patterns were similar between carcass types in the first $(P=0.003)$ and the second $(P=0.01)$ studies. The results of the development study of $P$. regina maggots in the field show that there was a significant difference between the distributions of length for maggots reared on loin tissue from ethanol-treated and untreated pigs. Maggots that fed on tissue from ethanol-treated pigs took $\approx 11.9 \mathrm{~h}$ longer to reach the pupal stage than maggots that fed on tissue from untreated pigs. The longer developmental time for maggots on tissue from ethanol-treated pigs was due mainly to the longer postfeeding period of the third instar.
\end{abstract}

KEY WORDS entomotoxicology, forensic entomology, successional pattern, development, Phormia regina

ENTOMOTOXICOLOGY IS AN EMERGING discipline within forensic science whereby entomological specimens collected postmortem are analyzed for the presence of drugs or toxins (Goff and Lord 2001). Toxicological data obtained by analyses of entomological specimens collected at an autopsy, or from the scene of death, can provide vital information for determining the cause of death (Goff and Lord 2001). Antemortem exposure to prescription or illicit drugs and other toxins may be the sole or contributing cause of death, thereby underscoring the importance of toxicological examinations of blood, urine, tissues, and other specimens collected as evidence by the pathologist (Beyer et al. 1980, Miller et al. 1994). In many drug- or alcohol-related deaths, decedents are not discovered until advanced stages of decomposition are apparent (Goff and Lord 2001). At that stage, blood, urine, tissue, and other biological fluids may not be available or may be

\footnotetext{
${ }^{1}$ College of Veterinary Medicine, Virginia Polytechnic Institute and State University, Blacksburg, VA 24061-0319.

${ }^{2}$ Toxicology Section, Division of Forensic Science, Western Laboratory, Roanoke, VA 24019.
}

unsuitable for reliable toxicological examination (Henssge and Knight 1995).

Carrion-feeding insects are usually present on, or in the vicinity of, decomposing remains long after tissue, blood, and urine become unsuitable for analysis. As such, drugs and toxins in decomposing tissue may be identified in insect tissue or remnants (e.g., puparial cases, frass, and excrement) as the result of continual feeding by these insects on the tissue (Sohal and Lamb 1977, 1979; Beyer et al. 1980; Nuorteva and Nuorteva 1982; Gunatilake and Goff 1989; Kintz et al. 1990).

Toxicological analysis of entomological specimens is conducted in a similar manner to traditional specimens, with procedures including radioimmunoassay, gas chromatography, thin-layer chromatography, and high-performance liquid chromatography-mass spectrometry. The entomotoxicological data from these analyses have been used successfully as indicators of cause and manner of death in a number of cases (Lord 1990, Nolte et al. 1992, Goff and Lord 1994). The reliability of toxicological analysis of entomological specimens therefore is well documented (Miller et al. 1994). 

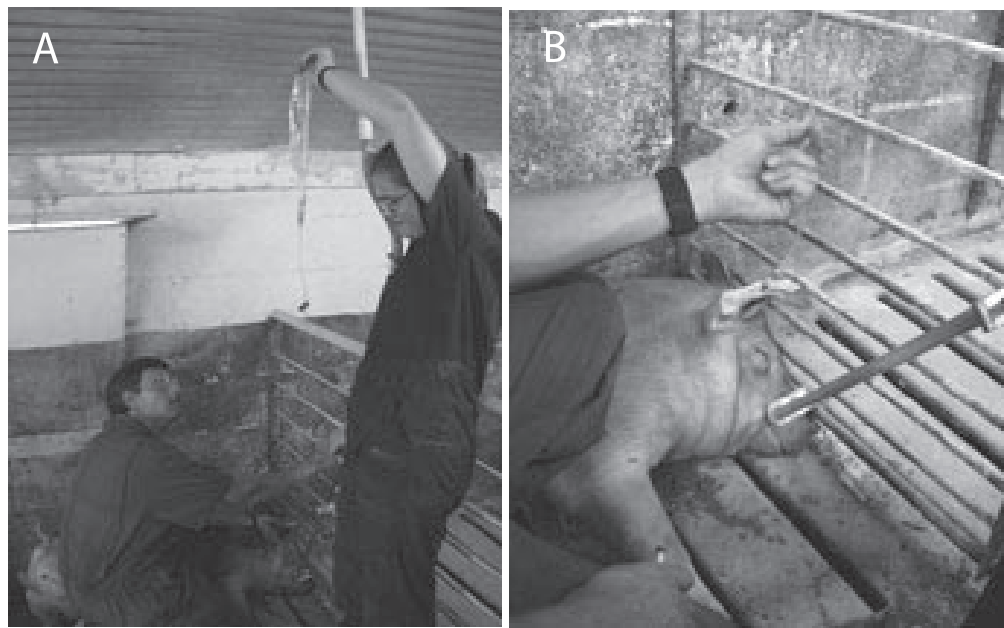

Fig. 1. Intravenous ear catheter used for antemortem dosing of pigs with ethanol for succession and development studies.

Studies show that antemortem use of various drugs and toxins can affect maggot developmental rate, resulting in the inaccurate estimation of postmortem interval (PMI) based on insect development (Goff et al. 1989, 1991, 1993; Hédouin et al. 1999). Errors of up to 38,48 , and $77 \mathrm{~h}$ were found to occur in PMI estimates with the presence of heroin (Goff et al. 1991), methamphetamine (Goff et al. 1992), and amitriptyline (Goff et al. 1993), respectively, in decomposing tissue. Whether ethanol or alcohol, in general, can alter the development and behavior of forensically important insects is unknown. A thorough search of the literature found no published studies of the effect of antemortem ethanol ingestion on the development or successional patterns of carrion insects.

The purpose of this study was to determine whether antemortem ingestion of ethanol affects postmortem successional patterns and development of insects on decomposing carcasses. The animal of choice for the study was the domestic pig, Sus scrofa L., because this species was found to be the most suitable for use as a human model in successional studies (Catts and Goff 1992). The effects of the presence of ethanol in carcass tissue on maggot development were examined under field conditions for the black blow fly, Phormia regina (Meigen).

\section{Materials and Methods}

Studies were conducted in Blacksburg, VA, in 2003 to examine the effects of antemortem ethanol ingestion on insect successional patterns and development of $P$. regina. Blacksburg is located in southwestern Virginia and is $\approx 608 \mathrm{~m}$ above sea level; average temperature in the area during the summer is $20.7^{\circ} \mathrm{C}$ (National Weather Service, www.nws.noaa.gov). Two successional studies were conducted. The first was conducted from 7 to 18 July (study 1 ) and the second from 22 to 31 July (study 2 ). The development study was conducted during the period of the second successional study.

Animals and Ethanol Dosing. Four commercially cross-bred pigs were obtained from the Swine Center at Virginia Tech for use in each successional study. The animals ranged in weight from 40 to $65 \mathrm{~kg}$. Two of the animals were administered ethanol before euthanasia, and the remaining two animals were untreated. Ethanol was administered orally and intravenously to achieve a blood alcohol concentration (BAC) that was above the legal human limit in most states in the United States (i.e., 0.08\%). The two pigs in the first study that were treated were initially fed a mixture of 80-proof Aristocrat vodka and fruit drink and allowed to drink until satiated. The amount of ethanol ingested corresponded to an intake of $\approx 60 \mathrm{ml}$ of vodka. A second method of administering ethanol was devised based on our observations, which suggested that a greater volume of ethanol was needed to achieve the desired BAC. Therefore, $30 \mathrm{~min}$ after drinking ceased, a butterfly catheter was inserted into an ear vein of each of the two pigs and an intravenous catheter was used to administer $90 \mathrm{ml}$ of $95 \%$ ethanol in 225-271 ml of saline over a 30-min period (Fig. 1). The amount of saline was adjusted for the weight of each animal. In the second study, $60 \mathrm{ml}$ of vodka in saline was administered via oral gavage to the two pigs selected for treatment after the ethanol solution was given intravenously. An oral gavage was used because the pigs in this study did not drink the ethanol-fruit drink mixture as willingly as the animals did in the first study.

Analysis of Blood and Tissue Samples. Antemortem blood samples were collected from the anterior vena cava from both treated and untreated pigs $15 \mathrm{~min}$ after ethanol dosing. Immediately after euthanasia by electrical shock, $\approx 1 \mathrm{~kg}$ of loin meat was excised from each of the pigs in the second succession study to be used as the rearing medium in the development study of 
P. regina maggots. Blood also was collected from the heart of each carcass $48 \mathrm{~h}$ postmortem because this organ contained a sufficient amount of uncoagulated blood.

Blood and tissue taken from the pigs and homogenate of maggot specimens collected during the succession studies were analyzed for ethanol by headspace gas chromatography using an HP 7694 HS Sampler configured to an Agilent GC-6890 Plus with a flame ionization detector (Agilent Technologies, Palo Alto, CA). The column was a Restek Rtx-BAC1, and $n$-propanol was used as the internal standard. Total run time was $4 \mathrm{~min}$, and the limit of detection (LOD) and limit of quantitation (LOQ) were both $0.01 \%$.

Insect Succession. After blood and tissue were extracted, the remainder of the pig carcass was transported immediately to the field site at Moore Farm, a research facility of Virginia Tech, which is $\approx 4 \mathrm{~km}$ from the Swine Center. The carcasses were placed individually under open-bottomed cages, which were located $100 \mathrm{~m}$ apart at the edge of an open field bordered by a thickly wooded area and were allowed to decompose for $10 \mathrm{~d}$. Each cage measured 92 by 92 by $153 \mathrm{~cm}$ and was constructed with $2.5-\mathrm{cm}$ steel-welded tubing and 1.27-cm hardware cloth (Tabor et al. 2004). Cages also were staked to the ground to prevent disturbance of the carcasses by scavengers.

Samples of adult insects were collected from 10 aerial net sweeps above and around the carcass, pitfall traps, and directly off the carcass to qualitatively assess insect fauna. Adult samples were placed with a paper towel saturated with ethyl acetate into individual 4.5 liter Hefty Onezip plastic bags (Pactiv Corp, Lake Forest, IL). In addition, we collected several clusters of fly eggs and several hundred maggots, when they were present, using soft-touch forceps. Half of each egg or maggot sample was placed directly into vials containing KAA fixative $(100 \mathrm{ml} 95 \%$ ethanol, $20 \mathrm{ml}$ glacial acetic acid, $10 \mathrm{ml}$ kerosene) (Haskell 1990). The remaining half of each egg or maggot sample was placed in an aluminum pouch containing ground pork (Haskell 1990). The pouches were then placed into $500 \mathrm{ml}$ MicroGourmet SOLO cups (Solo Cup Co., Urbana, IL) filled with $7 \mathrm{~cm}$ of Hoffman vermiculite (A. H. Hoffman, Inc., Lancaster, NY) to provide a substrate in which maggots could pupate. A mesh cloth was placed over a large hole cut in the lid of each cup to provide aeration while preventing maggots from escaping. The cups were placed into an incubator at $27^{\circ} \mathrm{C}, 75 \% \mathrm{RH}$ where eggs and maggots were reared to the adult stage. All collected and reared adults were pinned, labeled, and identified to genus or species. Voucher specimens were placed in the entomological collections at Virginia Tech.

Development Study. To attract wild-type flies for oviposition, the carcass of a pig, which was not used in the succession study, was placed outdoors at a location where $P$. regina is known to exist as the dominant blow fly species (Tabor et al. 2004). Twelve clusters of $P$. regina eggs were collected from the carcass within a 4 -h period on the second day postmortem. One hundred and seventy grams of the loin tissue removed from each of the four pigs used in the second succession study was placed in 500-ml cups, for a total of 12 cups (i.e., six cups with tissue from ethanol-treated pigs and six cups with tissue from untreated pigs). One egg cluster containing 100-200 eggs was then placed on the loin tissue in each cup.

Eggs were observed hourly to determine the initial hatch time $(t=0)$ for each cluster (cup). At the onset of egg hatch, the cups with loin tissue and eggs were transferred to 4.5-liter wax coated containers (Sweetheart Cup Company, Owings Mills, MD) filled with $10 \mathrm{~cm}$ of Hoffman vermiculite (A.H. Hoffman, Inc., Lancaster, NY). Holes were cut out of the cardboard lids, which locked into a lip on the inside of each container. A piece of gauze fabric was placed under the lid to cover the hole to prevent maggots from escaping. The containers were then covered with clear Saran Quickcovers (S. C. Johnson \& Son, Inc., Racine, WI) to maintain the humidity inside the cup to at least $80 \%$ and to prevent rain from getting inside the cups. The containers with rearing cups were placed outside in partial sunlight under a cage similar to the ones used in the succession studies to prevent scavenging. A plastic tarp was used to cover the cage when heavy rain was expected.

Samples of maggots were collected every $8 \mathrm{~h}$ until pupation, beginning at the onset of the earliest egg hatch among cups (egg clusters). A sample consisted of six randomly selected maggots per cup for a total of 18 maggots per cup per day. The maggots were placed directly into KAA for at least $1 \mathrm{~h}$ before measurements were taken. The fixative caused the maggots to extend fully so that they could be measured to the nearest $0.25 \mathrm{~mm}$ by using a small ruler. Length and instar (as determined by the number of spiracular slits) were recorded for each maggot.

Maggot sampling continued until $\approx 90 \%$ of the individuals in each cup had either been removed or pupated. Pupae were removed from the rearing cups as they were noted and placed in separate labeled containers. The time to complete the pupal stage also was recorded for each individual.

Data and Statistical Analysis. We used the methods described in Tabor et al. (2004) to characterize the successional patterns of insect taxa on ethanol-treated and untreated pig carcasses over the $10 \mathrm{~d}$ sampling period and to determine whether the patterns were similar. First, we combined the data on the arrival of insect taxa on ethanol-treated pigs from the two succession studies to develop a single succession diagram. A similar diagram of succession was developed for insect taxa on the untreated pig carcasses. From each of the succession diagrams, an occurrence matrix of ones and zeros was developed for the presence or absence, respectively, of an insect taxon within a sampling interval. Next, we calculated the overall or mean Jaccard similarity $\left(S_{\text {gmean }}\right)$ in the successional pattern of insect taxa and the precision of this metric (i.e., $S_{\text {gmean }} \pm 95 \%$ confidence limit [CL]) for each occurrence matrix using the Jackknife procedure described in Tabor et al. (2004). 
Similar values of $S_{\text {gmean }}$ for different occurrence matrices cannot be used to infer similar successional patterns of taxa (Tabor et al. 2004). Therefore, like Tabor et al. (2004), we used a permutation approach based on Mantel's test (Cheverud et al. 1989, Manly 1997) to test the null hypothesis of no similarity between the patterns of succession of insect taxa in the occurrence matrices developed for ethanol-treated and untreated pigs. The $P$ value for the test was determined by the position of the observed Pearson correlation coefficient $\left(K_{o b s}\right)$ between the Jaccard similarity matrices developed from the occurrence matrices for ethanol-treated and untreated pigs, in a distribution of correlation coefficients ( $K$ values). The distribution of $K$ values was generated by comparing the two Jaccard similarity matrices 999 times after corresponding rows and columns of one of the matrices was randomly permuted simultaneously.

For analysis of the development data for P. regina, we plotted the maggot length versus time for maggots feeding on tissue from ethanol-treated and untreated pigs. A second order polynomial was fitted to each of the data sets by using TableCurve 5.01 (SYSTAT Software Inc., Richmond, CA). Statistical differences $(\alpha=$ $0.05)$ between the distribution functions for maggot length for individuals that fed on loin tissue from ethanol-treated and untreated pigs were determined separately for each of the three instars and for all instars combined using a Kolmogorov-Smirnov test (Conover 1999).

\section{Results}

Detectable concentrations of ethanol were found in samples of antemortem and postmortem blood and in loin tissue taken from ethanol-treated pigs, but they were found only in the postmortem blood samples of untreated pigs. In addition, the BACs in the samples of antemortem and postmortem blood from the ethanoltreated pigs were all $>0.08 \%$, the legal human limit in many states in the U.S. (Table 1).

The successional patterns of insect taxa on carcasses of ethanol-treated and untreated pigs during 10 sampling intervals are shown in Fig. 2. Each diagram in Fig. 2 represents the combined occurrence of insect taxa for the two succession studies (i.e., on four pig carcasses for each treatment). Mean (range) ambient temperatures during study one and study two were $21.9(12.6-31.4)$ and $20.2^{\circ} \mathrm{C}\left(12.2-30.2^{\circ} \mathrm{C}\right)$, respectively.

A total of 32 insect taxa were observed during the two succession studies (Fig. 2). Of these, 29 and 27 taxa were observed on the carcasses of ethanol-treated and untreated pigs, respectively. The earliest visitors to both carcass types were dipterans in the families Calliphoridae, Sarcophagidae, and Muscidae. Adult flies and eggs were collected from all carcasses by the end of the first day after placement in the field. By day 10 , all of the carcasses in both studies had reached advanced decay.

Dipterans were represented by 19 taxa in six families. Six of the seven blow fly species were collected
Table 1. Concentrations of ethanol (\% wt by vol) in blood and loin tissue of the pigs used in the two studies

\begin{tabular}{cclccc}
\hline \hline Study & Pig & Treatment & $\begin{array}{c}\text { Antemortem } \\
\text { blood }\end{array}$ & $\begin{array}{c}48 \mathrm{~h} \\
\text { Postmortem } \\
\text { blood }\end{array}$ & $\begin{array}{c}\text { Loin } \\
\text { tissue }\end{array}$ \\
\hline 1 & 1 & Ethanol & 0.14 & 0.11 & 0.07 \\
& 2 & Ethanol & 0.16 & 0.10 & 0.07 \\
& 3 & Untreated & ND & 0.02 & ND \\
& 4 & Untreated & ND & 0.01 & ND \\
2 & 1 & Ethanol & 0.26 & 0.20 & 0.15 \\
& 2 & Ethanol & 0.23 & 0.21 & 0.17 \\
& 3 & Untreated & ND & 0.03 & ND \\
& 4 & Untreated & ND & 0.01 & ND \\
& & & & &
\end{tabular}

ND, not detected with an LOD and LOQ of $0.01 \%$.

from the carcasses of both ethanol-treated and untreated pigs (Fig. 2), with $P$. regina (Calliphoridae) and $P$. coeruleiviridis (Calliphoridae) being the most commonly collected species. Similarly, all of the Muscidae, Sepsidae, Piophilidae, and Phoridae were collected from the remains of both ethanol-treated and untreated pigs. Only one of the two genera of Sarcophagidae was collected on both carcass types.

Thirteen taxa of coleopterans in six families were observed with taxa from all of the six families collected from the carcasses of ethanol-treated pigs (Fig. 2). However, taxa from only three of the beetle families were collected from the carcasses of untreated pigs. The dominant beetle species on both carcass types were Creophilis maxillosus L. (Staphylinidae) and Oiceoptoma noveboracense Forster (Silphidae). Latearriving taxa in the families Cleridae, Trogidae, and Dermestidae were collected only from the carcasses of ethanol-treated pigs.

Jackknife estimates of overall Jaccard similarities $\left(\hat{S}_{\text {gmean }} \pm 95 \% \mathrm{CL}\right)$ for the successional patterns of insect taxa on the carcasses of ethanol-treated animals were $0.33 \pm 0.117$ and $0.28 \pm 0.120$ for study 1 and study 2 , respectively. Overall Jaccard similarities for the successional patterns of insect taxa on carcasses of the untreated pigs were $0.32 \pm 0.098$ and $0.30 \pm 0.150$ for study 1 and study 2 , respectively. Permutation analyses detected no differences between the successional patterns of insect taxa on carcasses of ethanoltreated and untreated pigs in study $1\left(K_{o b s}=0.64 ; P=\right.$ $0.003)$ and study $2\left(K_{o b s}=0.68 ; P=0.001\right)$.

The development of $P$. regina maggots feeding on tissue from ethanol-treated and untreated pigs under field conditions is shown in Fig. 3. Mean \pm SD time required by $P$. regina maggots feeding on tissue from ethanol-treated and untreated pigs to reach the pupal stage was $145.5 \pm 14.8$ and $133.6 \pm 11.6 \mathrm{~h}$, respectively (Table 2). Mean \pm SD duration of development of pupae from maggots that fed on tissue from ethanoltreated and untreated pigs was $147.3 \pm 11.4$ and $143.9 \pm 8.3 \mathrm{~h}$, respectively.

The best fit models to the data on maggot length and the stadial durations are presented in Figs. 3 and 4. The Kolmogorov-Smirnov test found that the distribution of maggots lengths was significantly different for mag- 


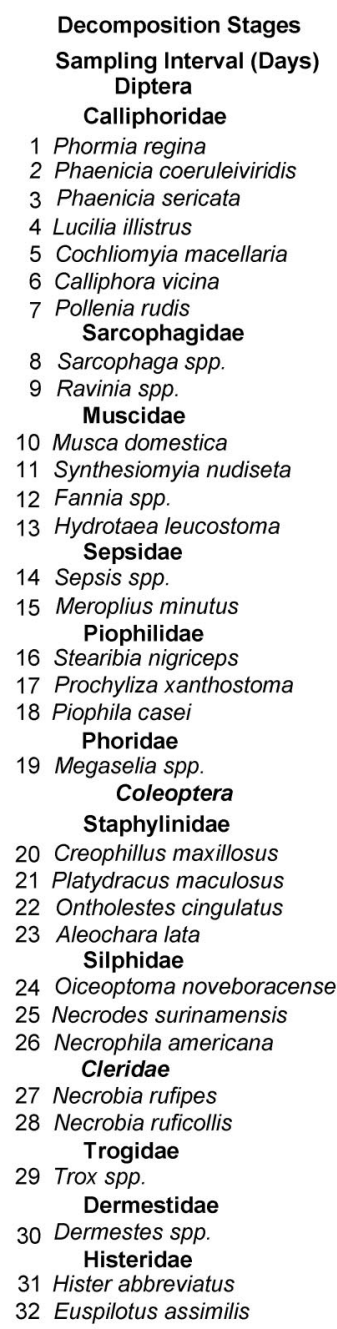
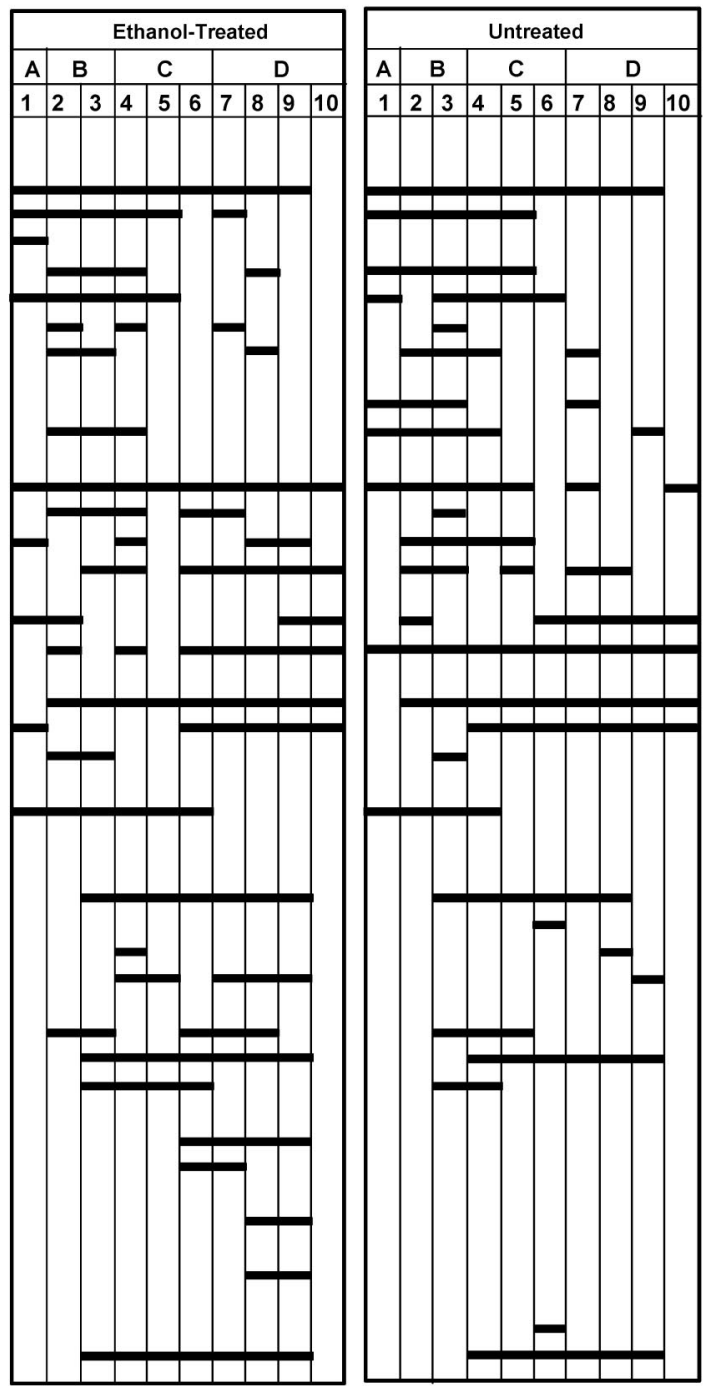

Fig. 2. Succession diagram for ethanol-treated and untreated pig carcasses during 10 sampling intervals in summer 2003 in Blacksburg, VA. Stage of decomposition are shown and are (A) fresh, (B) bloat, (C) active decay, and (D) advanced decay and dry.

gots feeding on loin tissue from ethanol-treated pigs and untreated pigs $\left(D_{\max }=0.2882 ; \mathrm{df}=146,170 ; P<\right.$ $0.05)$. No differences were detected in the distribution of maggot lengths for first $\left(D_{\max }=0.1622 ; \mathrm{df}=27,37\right.$; $P>0.05)$ or second $\left(D_{\max }=0.2542 ; \mathrm{df}=49,59 ; P>\right.$ $0.05)$ instars, which fed on loin tissue from ethanoltreated and untreated pigs. However, differences were detected in maggot length for the third instar feeding on the two types of loin tissue $\left(D_{\max }=0.3798\right.$; df $=113,129 ; P<0.05)$.

\section{Discussion}

Insect taxa observed on the pig carcasses in the two succession studies were typical of those found on carrion in southwestern Virginia during a similar period (Tabor et al. 2004). For example, Tabor et al.
(2004) also found that $P$. regina and P. coeruleiviridis were the most dominant species of blow flies during the summer. Both our study and that of Tabor et al. (2004) also found that Phaenicia sericata (Meigen) (Calliphoridae) and Calliphora vicina Robineau-Desvoidy (Calliphoridae) are likely to occur rarely on carcasses in the area during the summer. Any differences in insect taxa observed in our study and that of Tabor et al. (2004) could be attributed to the presence of rare taxa (i.e., taxa observed during $<30 \%$ of the sampling intervals in both studies). The only exception to this was Megaselia spp. (Phoridae), which were not identified by Tabor et al. (2004), but were found during 60 and $40 \%$ of the sampling intervals on ethanol-treated and untreated pigs, respectively (Fig. 2).

The overall Jaccard similarity coefficients for the successional patterns of insect taxa on ethanol-treated 


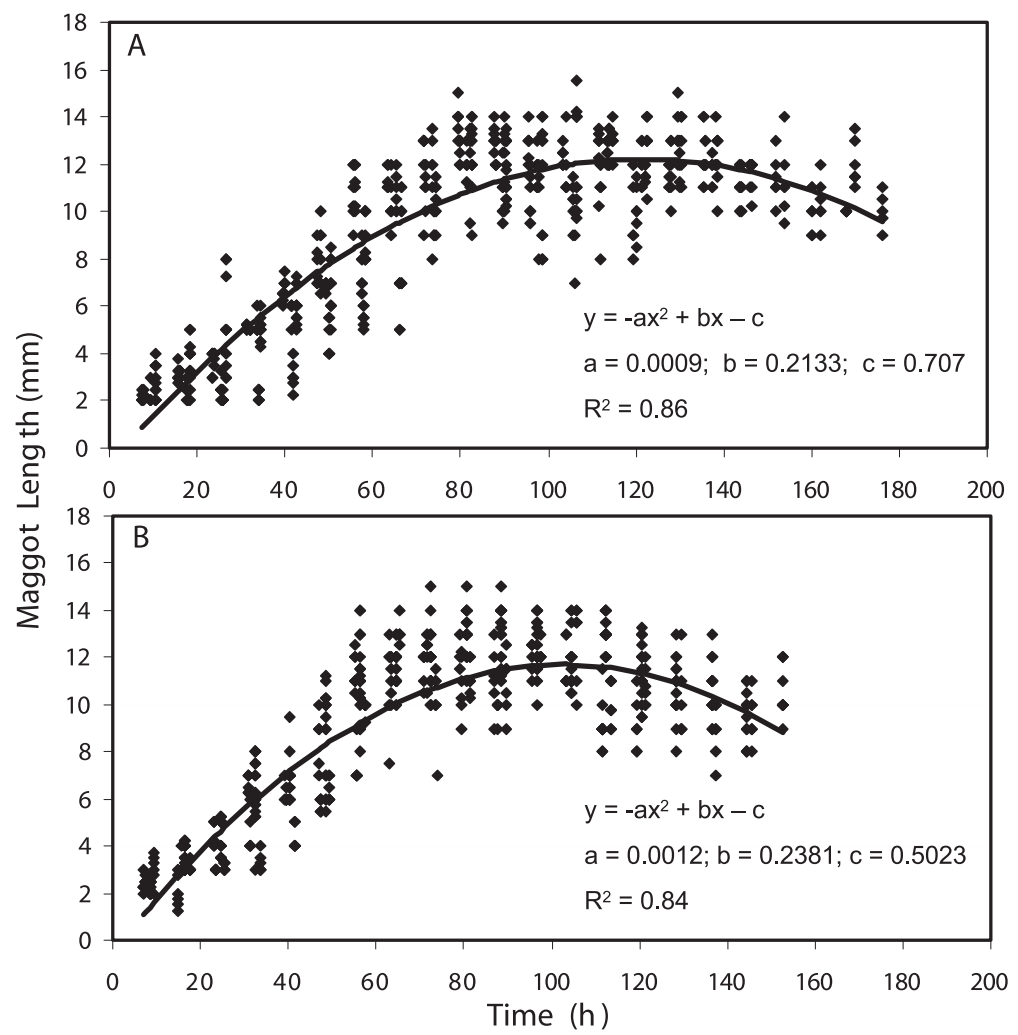

Fig. 3. Fitted curves of lengths of maggots feeding on loin tissue from ethanol-treated (A) and untreated (B) pigs.

( 0.33 and 0.28 for the first and second studies, respectively) and untreated animals ( 0.32 and 0.30 for the first and second studies, respectively) indicate the low similarity in taxa among sampling intervals within each of the studies. Tabor et al. (2004) found overall similarity coefficients of $\approx 0.30$ for the successional patterns of insect taxa on pig carcasses during the summer in southwestern Virginia. These similarity coefficients are typical for succession studies of insects in which the taxonomic composition changes according to the stage of decomposition (Reed 1958, Payne 1965, Schoenly 1992). In hot weather conditions, as during the summer in southwestern Virginia, carcass decomposition and changes in taxonomic composition progress more rapidly than under cooler conditions (Tabor et al. 2004).

Table 2. Time from egg eclosion to completion of stage for $P$. regina reared on loin tissue from ethanol-treated and untreated pigs

\begin{tabular}{lcc}
\hline \multicolumn{1}{c}{ Stage } & $\begin{array}{c}\text { Loin tissue from } \\
\text { ethanol-treated pigs } \\
\text { (range [mean } \pm \text { SD] h) }\end{array}$ & $\begin{array}{c}\text { Loin tissue from } \\
\text { untreated pigs } \\
\text { (range [mean } \pm \text { SD] h) }\end{array}$ \\
\hline First instar & $18.5-42.0(27.6 \pm 7.8)$ & $16.5-33.5(24.8 \pm 6.6)$ \\
Second instar & $47.5-66.5(55.2 \pm 7.2)$ & $40.5-74.0(52.4 \pm 10.2)$ \\
Third instar & $127.5-176.0(145.5 \pm 14.8)$ & $119.5-152.5(133.6 \pm 11.6)$ \\
\hline
\end{tabular}

${ }^{a}$ Feeding and prepupal stages combined.
Antemortem ingestion of ethanol by pigs did not seem to alter the successional patterns of insect taxa on the decomposing carcasses. The permutation analyses indicated that the successional patterns on carcasses of ethanol-treated pigs were similar to those on carcasses of untreated pigs. Also, no apparent differences were observed in decomposition rates between ethanol-treated and untreated animals. As such, insect visitation and colonization occurred at the same rate for ethanol-treated and untreated pigs, even when antemortem blood ethanol concentration was as high as $0.26 \%$, which is $>3$ times the legal human limit in many U.S. states.

The presence of taxa in the beetle families Cleridae, Trogidae, and Dermestidae on the carcasses of ethanol-treated pigs and their absence from the carcasses of untreated pigs were not sufficient to create statistical differences between the successional patterns. This may be because the occurrences of beetles in the three families were relatively low on the carcasses of ethanol-treated pigs. With the exception of the clerid beetles, which were collected from carcasses of ethanol-treated pigs during the two succession studies, specimens of Trogidae and Dermestidae were only collected at two sampling intervals in one of the studies. The low occurrence of beetles in the families Cleridae, Trogidae, and Dermestidae on pig carcasses has been observed previously during the spring and 


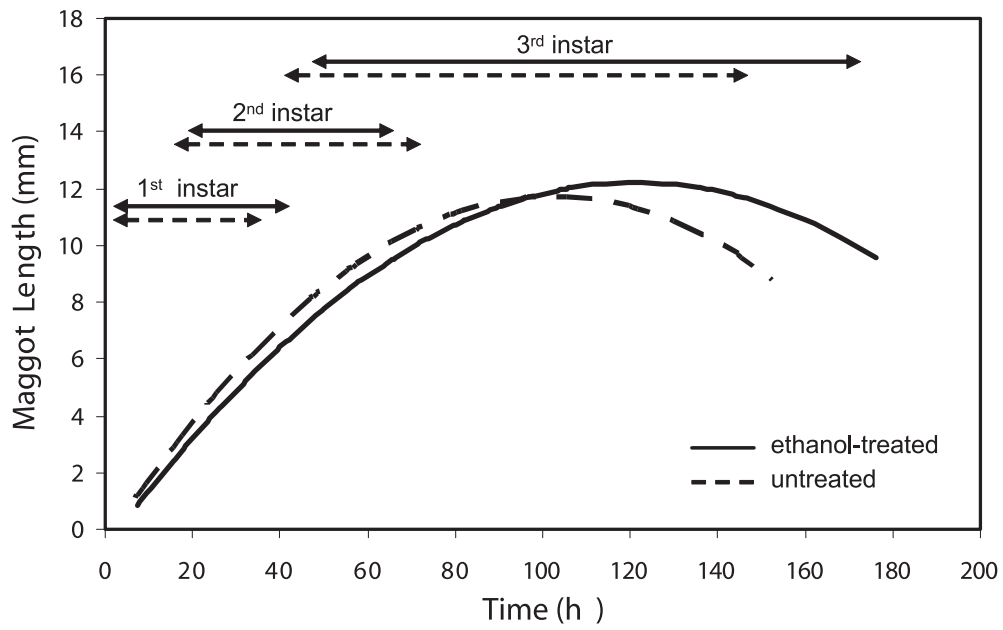

Fig. 4. Combined fitted curves for length and stadial duration of maggots feeding on loin tissue from ethanol-treated and untreated pigs.

summer in southwestern Virginia (Tabor et al. 2004, 2005).

In development-based PMI estimation, it is assumed that insects feeding on carrion will develop at predictable rates depending on environmental conditions. However, a number of studies have demonstrated that antemortem ingestion of some drugs and toxins can alter developmental rates of insects feeding on decomposed tissue from cadavers. Failure to account for such drug/toxin ingestion can result in an inaccurate PMI estimation. Goff et al. (1991) reported that the differences in rates of development of flesh fly Boettcherisca peregrine larvae reared on tissue obtained from rabbits that received varying doses of heroin before death were significant enough to alter PMI estimates based on larval and pupal development by up to 29 and $18-38 \mathrm{~h}$, respectively. Similar results were reported for methamphetamine (Goff et al. 1992) and amitriptyline (Goff et al. 1993). The effect of ethanol on maggot development has not been reported previously for forensically important flies. However, as was found in this study, antemortem ingestion of ethanol does affect the development of the black blow fly.

The time required for maggots feeding on tissue from ethanol-treated and untreated pigs to reach the pupal stage differed between the two treatments. Maggots feeding on tissue from ethanol-treated pigs required $\approx 11.9 \mathrm{~h}$ more, on average, to reach the pupal stage. The differences occurred mainly because third instars feeding on loin tissue from ethanol-treated pigs took significantly longer to enter the postfeeding stage compared with individuals that fed on tissue from untreated pigs. These results are consistent with those of other studies in which maggot development was shown to be affected by the presence of drugs or toxins in tissue on which they fed. For example, Goff et al. (1991) found that the presence of heroin in tissue affected maggot growth during the later stages but not during the early stages of development.
The time required by $P$. regina maggots feeding on loin tissue from untreated pigs to reach the pupal stage was shorter than has been recorded in other studies. For example, Anderson (2000) found that maggots took $217-268 \mathrm{~h}$ to reach the pupal stage at a constant temperature of $23^{\circ} \mathrm{C}$, which is close to the mean temperature $\left(20.2^{\circ} \mathrm{C}\right)$ recorded during our study. Byrd and Allen (2001) found that maggots required an average of 359 and $320 \mathrm{~h}$ to reach the pupal stage at constant temperatures of 20 and $25^{\circ} \mathrm{C}$, respectively; maggots required $339 \mathrm{~h}$ to reach the pupal stage under cycling temperatures of $35-15^{\circ} \mathrm{C}$. The development of forensically important species can be affected by factors such as the type of larval food source (Byrd 2001) and the temperature regime to which individuals are exposed (Higley and Haskell 2001). Anderson (2000), for example, used beef liver as a rearing media, but maggots collected in our study were reared on loin tissue from pig carcasses. Also, maggots in our study were reared under fluctuating temperatures in the field and not constant or cycling temperature regimes in the laboratory as was done by Byrd and Allen (2001).

Factors that affect postmortem larval length, a measure of larval age, also can affect the accuracy of development-based PMI estimates (Adams and Hall 2003). One such factor is the method of killing and preservation of the maggots collected from a corpse. Adams and Hall (2003), for example, found that preservatives containing high concentrations of ethanol, such as the KAA fixative used in our study, can cause significant postmortem expansion in larval length. Fortunately, all of the specimens collected from ethanoltreated and untreated pigs in our study were treated similarly, and, in addition, our objective was not to estimate PMI but to show that carcass tissue containing substances such as alcohol can alter the development of carrion-feeding insects.

The ethanol concentrations detected in the loin tissue taken from pigs in the second study ( 0.15 and 
$0.17 \%$ ) were observed from animals with an antemortem blood ethanol concentrations of 0.26 and $0.23 \%$, respectively. These BACs are consistent with postmortem concentrations observed in human specimens (Garriott 1996), thus demonstrating relevant comparison with actual alcohol-related deaths. Pathologists are often confounded with interpreting BACs when endogenous production of ethanol by microbial synthesis occurs in vivo in putrefying bodies. This results in the detection of artifactual ethanol in toxicological analyses (Gilliland and Bost 1993). In this study, postmortem BACs for untreated carcasses yielded detectable amounts of ethanol; however, the concentrations were much lower than in the treated pigs ( $\leq 0.03 \%$ for untreated and $0.10-0.21 \%$ for ethanoltreated animals). Ethanol was not detected in the loin tissue from untreated carcasses. The BAC finding in untreated animals is consistent with the postmortem neoformation of ethanol during decomposition. Vitreous humor from the eyes, encased within the bony orbits of the skull, and urine, ordinarily obtained from the sterile bladder, are two specimen types from anatomical sites that can assist the forensic toxicologist in interpreting the significance of ethanol detected in a blood specimen that is suspected to be putrefied in quality (Levine 1999).

This study provides information on the effect of antemortem ingestion of ethanol on insect successional patterns and the development of $P$. regina. The results suggest that although ethanol consumption by an individual is likely to have no apparent effect on the successional pattern of insect fauna on the decomposing remains, the presence of ethanol in tissue of the remains can affect the development of maggots and potentially estimates of the PMI.

\section{Acknowledgments}

We thank Ricky Dove, Rodney Hare, and Cindy Wood (Swine Center at Virginia Tech) for providing and housing the pigs used in the studies; Scotty Bolling for constructing the cages; Martha Tubman and Marie Pelzer for assistance in the studies; and the Governor's School for Agriculture students for help with data collection. We also thank Joey Wiley for assistance with laboratory analysis. This project was reviewed and approved by the Animal Care Committee at Virginia Tech.

\section{References Cited}

Adams, Z.J.O., and M.J.R. Hall. 2003. Methods used for the killing and preservation of blowfly larvae, and their effect on post-mortem larval length. Forensic Sci. Int. 138: 5061.

Anderson, G. S. 2000. Minimum and maximum development rates of some forensically important Calliphoridae (Diptera). J. Forensic Sci. 45: 824-832.

Beyer, J. C., W. F. Enos, and M. Stajić. 1980. Drug identification through analysis of maggots. J. Forensic Sci. 25: 411- 412 .

Byrd, J. H. 2001. Laboratory rearing of forensic insects, pp 121-142. In J. H. Byrd and J. L. Castner [eds.], Forensic entomology: the utility of arthropods in legal investigations. CRC, Boca Raton, FL.
Byrd, J. H., and J. C. Allen. 2001. The development of the black blow fly, Phormia regina (Meigen). Forensic Sci. Int. 120: 79-88.

Catts, E. P., and M. L. Goff. 1992. Forensic entomology in criminal investigations. Annu. Rev. Entomol. 37: 253-272.

Cheverud, J. M., G. P. Wagner, and M. M. Dow. 1989. Methods for the comparative analysis of variation patterns. Syst. Zool. 38: 201-213.

Conover, W. J. 1999. Practical nonparametric statistics. Wiley, New York.

Garriott, J. 1996. Analysis for alcohol in postmortem specimens, pp. 151-169. In J. Garriott [ed.], Medicolegal aspects of alcohol, 3rd ed. Lawyers \& Judges Publishing Co., Inc., Tucson, AZ.

Gilliland, M.G.F., and R. O. Bost. 1993. Alcohol in decomposed bodies: postmortem synthesis and distribution. J. Forensic Sci. 38: 1266-1274.

Goff, M. L., A. I. Omori, and J. R. Goodbrod. 1989. Effect of cocaine in tissues on the development rate of Boettcherisca peregrina (Diptera: Sarcophagidae). J. Med. Entomol. 26: 91-93.

Goff, M. L., W. A. Brown, K. A. Hewadikaram, and A. I. Omori. 1991. Effect of heroin in decomposing tissues on the development rate of Boettcherisca peregrina (Diptera, Sarcophagidae) and implications of this effect on estimation of postmortem intervals using arthropod development patterns. J. Forensic Sci. 36: 537-542.

Goff, M. L., W. A. Brown, and A. I. Omori. 1992. Preliminary observations of the effect of methamphetamine in decomposing tissues on the development of Parasarcophaga ruficornis (Diptera: Sarcophagidae) and implications of this effect on the estimations of postmortem intervals. J. Forensic Sci. 37: 867-872.

Goff, M. L., W. A. Brown, A. I. Omori, and D. A. LaPointe. 1993. Preliminary observations of the effects of amitriptyline in decomposing tissues on the development of Parasarcophaga ruficornis (Diptera: Sarcophagidae) and implications of this effect to estimation of postmortem interval. J. Forensic Sci. 38: 316-322.

Goff, M. L., and W. D. Lord. 1994. Entomotoxicology: a new area for forensic investigation. Am. J. Forensic Med. Pathol. 15: 51-57.

Goff, M. L., and W. D. Lord. 2001. Entomotoxicology, pp. 331-340. In J. H. Byrd and J. L. Castner [eds.], Forensic entomology: the utility of arthropods in legal investigations. CRC, Boca Raton, FL.

Gunatilake, K., and M. L. Goff. 1989. Detection of organophosphate poisoning in a putrefying body by analyzing arthropod larvae. J. Forensic Sci. 34: 714-716.

Haskell, N. H. 1990. Procedures in the entomology laboratory, pp. 111-123. In E. P. Catts and N. H. Haskell [eds.]. Forensic Entomology Specialties. Clemson, SC.

Hédouin, V., B. Bourel, L. Martin-Bouyer, A. Becart, G. Tournel, M. Deveaux, and D. Gosset. 1999. Morphine perfused rabbits: a tool for experiments in forensic entomotoxicology. J. Forensic Sci. 44: 347-350.

Henssge, C., and B. Knight. 1995. Estimation of the time since death in the early postmortem interval. Oxford University Press, Oxford, England.

Higley, L. G., and N. H. Haskell. 2001. Insect development and forensic entomology, pp. 287-302. In J. H. Byrd and J. L. Castner [eds.], Forensic entomology: the utility of arthropods in legal investigations. CRC, Boca Raton, FL.

Kintz, P., B. Godelar, A. Tracqui, P. Mangin, A. A. Lugnier, and A. J. Chaumont. 1990. Fly larvae: a new toxicological method of investigation in forensic medicine. J. Forensic Sci. 35: 204-207. 
Levine, B. [ed.] 1999. Principles of forensic toxicology. American Association for Clinical Chemistry, Inc., Washington, DC.

Lord, W. D. 1990. Case histories of the use of insects in investigations, pp. 9-37. In E. P. Catts and N. H. Haskell [eds.], Entomology and death: a procedural guide. Joyce's Print Shop, Inc., Clemson, SC.

Manly, B.F.J. 1997. Randomization, bootstrap and Monte Carlo methods in biology. Chapman \& Hall, Boca Raton, FL.

Miller, M. L., W. D. Lord, M. L. Goff, B. Donnelly, E. T. McDonough, and J. C. Alexis. 1994. Isolation of amitriptyline and nortriptyline from fly puparia (Phoridae) and beetle exuviae (Dermestidae) associated with mummified human remains. J. Forensic Sci. 39: 13051313.

Nolte, K. B., R. D. Pinder, and W. D. Lord. 1992. Insect larvae used to detect cocaine poisoning in a decomposed body. J. Forensic Sci. 37: 1179-1185.

Nuorteva, P., and S. L. Nuorteva. 1982. The fate of mercury in sarcosaprophagous flies and in insects eating them. Ambio 11: 34-37.

Payne, J. A. 1965. A summer carrion study of the baby pig Sus scrofa Linnaeus. Ecology 46: 592-602.
Reed, H. B. 1958. A study of dog carcass communities in Tennessee, with special reference to the insects. Am. Mid. Nat. 59: 213-245.

Schoenly, K. 1992. A statistical analysis of successional patterns in carrion-arthropod assemblages: implications for forensic entomology and determination of the postmortem interval. J. Forensic Sci. 37: 1489-1513.

Sohal, R. S., and R. E. Lamb. 1977. Intracellular deposition of metals in the midgut of the adult housefly, Musca domestica. J. Insect Physiol. 23: 1349-1354.

Sohal, R. S., and R. E. Lamb. 1979. Storage-excretion of metallic cations in the adult housefly, Musca domestica. J. Insect Physiol. 25: 119-124.

Tabor, K. L., C. C. Brewster, and R. D. Fell. 2004. Analysis of the successional patterns of insects on carrion in southwest Virginia. J. Med. Entomol. 41: 785-795.

Tabor, K. L., R. D. Fell, and C. C. Brewster. 2005. Insect fauna visiting carrion in southwest Virginia. Forensic Sci. Int. (in press).

Received 13 August 2004; accepted 15 January 2005. 